\title{
Expression of $\alpha$-methylacyl coenzyme A racemase in the dysplasia carcinoma sequence associated with Barrett's esophagus
}

\author{
Stefanie Scheil-Bertram ${ }^{1}$, Dietmar Lorenz ${ }^{2}$, Christian Ell ${ }^{3}$, Elena Sheremet ${ }^{1}$ and \\ Annette Fisseler-Eckhoff ${ }^{1}$ \\ ${ }^{1}$ Institute of Pathology and Cytology, HSK Wiesbaden, Academic Hospital of University of Mainz, Wiesbaden, \\ Germany; ${ }^{2}$ Department of Abdominal Surgery, HSK Wiesbaden, Academic Hospital of University of Mainz, \\ Wiesbaden, Germany; ${ }^{3}$ Department of Internal Medicine II, HSK Wiesbaden, Academic Hospital of University \\ of Mainz, Wiesbaden, Germany
}

\begin{abstract}
Two different studies demonstrated $\alpha$-methylacyl coenzyme A racemase (AMACR) to be a highly specific marker in Barrett's neoplastic lesions. Reactive atypia was positive in $3 / 30$ cases in these studies. We present a retrospective study of early Barrett's adenocarcinoma treated with surgery $(2000-2005, n=29 ; \mathrm{M}: \mathrm{F}=5: 1$, median age 67 years). We analyzed the role of AMACR expression in reactive and neoplastic lesions associated with the disease of 77 different specimens (60 biopsy and 17 surgical specimens) of these patients. In our cohort, $\mathbf{7 0} \%$ of cases demonstrated infiltration of the submucosa, $38 \%$ were poorly differentiated, and/or $31 \%$ demonstrated lymph vessel infiltration. We used a multi-tissue array, with reactive and neoplastic samples for each patient to analyze the immunoreactivity of AMACR. Barrett's epithelium that was negative for dysplasia and columnar epithelial cell changes indefinite for dysplasia $(n=30)$ did not demonstrate AMACR immunoreactivity. AMACR immunoreactivity was demonstrated in $27 \%(8 / 30)$ of cases of Barrett's epithelium with columnar epithelial cell changes indefinite for dysplasia. Altogether $91 \%$ of cases with low-grade dysplasia were AMACR-positive and $96 \%$ of cases with high-grade dysplasia and early Barrett's adenocarcinoma were positive for AMACR. In summary, the sensitivity of AMACR expression in low-grade dysplasia and subsequent early Barrett's adenocarcinoma was significantly higher in our study compared with previous data. This might be a new diagnostic marker for dysplasia carcinoma sequence in Barrett's low-grade neoplastic lesions. Further studies are required to investigate this point with well-defined controls having at least 5 -years follow-up. Modern Pathology (2008) 21, 961-967; doi:10.1038/modpathol.2008.73; published online 23 May 2008
\end{abstract}

Keywords: AMACR; Barrett; LGIN

The prevalence of Barrett's esophagus in patients with gastroesophageal reflux disease is $2.3-2.4 \% .^{1,2}$ This represents the most serious histological consequence of gastroesophageal reflux disease. Barrett's disease is an established precursor to esophageal adenocarcinoma. In Germany, the incidence of adenocarcinoma in Barrett's esophagus is $0.4-1.7 \% .^{3}$ Although most patients with Barrett's esophagus do not progress to adenocarcinoma, those with progression have a poor prognosis. ${ }^{4}$

Correspondence: Dr S Scheil-Bertram, MD, PD, Institute of Pathology and Cytology, Dr Horst Schmidt Clinic Wiesbaden, Academic Hospital of University of Mainz, Ludwig Erhard Strasse 100, D-65199 Wiesbaden, Germany.

E-mail: scheil-bertram@pathologie-wiesbaden.de

Received 14 July 2007; revised 06 February 2008; accepted 10

February 2008; published online 23 May 2008
Endoscopic resection has been recommended as a local curative approach for (unicentric) mucosal Barrett's adenocarcinoma ( $\mathrm{m} 1$ or $\mathrm{m} 2$, and $\mathrm{m} 3$ without lymph vessel infiltration). ${ }^{5}$ Surgery is still the therapy of choice in early Barrett's adenocarcinoma infiltrating submucosal layers or poorly differentiated tumors because of a higher risk of lymph-node metastasis. ${ }^{6}$

Recently, two studies focused on $\alpha$-methylacyl coenzyme A racemase (AMACR) in Barrett's neoplastic lesions, an enzyme known to be expressed in prostate and colon cancer. ${ }^{7-9}$ AMACR catalyzes the racemization of $\alpha$-methyl-branched carboxylic coenzyme A thioesters. This protein was originally identified in the mitochondria and peroxisomes of rat liver cells. ${ }^{10}$ Previous studies demonstrated the expression of AMACR to be a highly specific marker in Barrett's neoplastic lesions. $^{7,8}$ Columnar epithelial cell changes 
indefinite for dysplasia were positive in $3 / 30$ cases in these studies. Follow-up was available for 11 of these patients with columnar epithelial cell changes indefinite for dysplasia. After 2 months, Barrett's adenocarcinoma was diagnosed in $1 / 3$ AMACR immunoreactive columnar epithelial cell changes indefinite for dysplasia patients. There was no follow-up in the other two patients.

In this retrospective study, we analyzed 29 cases of early Barrett's adenocarcinoma treated with surgery. We immunohistochemically stained all cases with AMACR. The aim of this study is to analyze whether AMACR expression could be a new diagnostic marker for dysplasia carcinoma sequence in Barrett's low-grade neoplastic lesions.

\section{Materials and methods}

\section{Cases}

The 29 cases found in this retrospective study of early Barrett's adenocarcinoma treated with surgery

Table 1 Clinical characteristics of 29 patients with early Barrett's adenocarcinoma

\begin{tabular}{|c|c|c|c|c|c|c|c|c|c|}
\hline Case & Age & Sex & Grade & $p T$ & $\mathrm{~m} / \mathrm{sm}$ & $L N+$ & $\begin{array}{l}L N \\
\text { (n) }\end{array}$ & $p L$ & $p V$ \\
\hline 44 & 67 & M & 1 & $1 \mathrm{a}$ & $\mathrm{m} 1$ & 0 & 23 & L0 & Vo \\
\hline 17 & 76 & $\mathrm{M}$ & 1 & $1 \mathrm{a}$ & $\mathrm{m} 1$ & 0 & 17 & L0 & Vo \\
\hline 11 & 73 & $\mathrm{M}$ & 2 & $1 \mathrm{a}$ & $\mathrm{m} 1$ & 0 & 7 & L0 & V0 \\
\hline 5 & 53 & $\mathrm{M}$ & 1 & $1 \mathrm{a}$ & $\mathrm{m} 3$ & 0 & 31 & L0 & V0 \\
\hline 7 & 75 & $\mathrm{M}$ & 1 & $1 \mathrm{a}$ & $\mathrm{m} 3$ & 0 & 19 & L0 & Vo \\
\hline 29 & 64 & M & 2 & $1 \mathrm{a}$ & m3 & 0 & 22 & L0 & Vo \\
\hline 54 & 81 & $\mathrm{M}$ & 2 & $1 \mathrm{a}$ & $\mathrm{m} 3$ & 0 & 28 & L0 & V0 \\
\hline 14 & 74 & $\mathrm{~F}$ & 2 & $1 b$ & $\mathrm{~m} 3$ & 0 & 31 & L0 & V0 \\
\hline 1 & 56 & $\mathrm{M}$ & 1 & $1 b$ & sm1 & 0 & 23 & L0 & V0 \\
\hline 38 & 65 & M & 1 & $1 b$ & $\operatorname{sm} 1$ & 0 & 27 & L0 & Vo \\
\hline 34 & 65 & $\mathrm{~F}$ & 2 & $1 b$ & $\mathrm{sm} 1$ & 0 & 18 & L0 & Vo \\
\hline 2 & 70 & $\mathrm{M}$ & 3 & $1 b$ & sm1 & 0 & 32 & L0 & V0 \\
\hline 24 & 61 & $\mathrm{M}$ & 3 & $1 b$ & sm1 & 1 & 40 & L1 & V1 \\
\hline 25 & 71 & $\mathrm{M}$ & 3 & $1 b$ & sm1 & 0 & 12 & L0 & V0 \\
\hline 53 & 73 & $\mathrm{M}$ & 3 & $1 b$ & $\mathrm{sm} 1$ & 0 & 20 & L1 & V0 \\
\hline 65 & 78 & $\mathrm{M}$ & 2 & $1 b$ & $\mathrm{sm} 2$ & 0 & 25 & L0 & Vo \\
\hline 64 & 79 & $\mathrm{~F}$ & 3 & $1 b$ & $\mathrm{sm} 2$ & 0 & 24 & L0 & V0 \\
\hline 0 & 52 & $\mathrm{M}$ & 1 & $1 b$ & $\mathrm{sm} 3$ & 0 & 19 & L0 & V0 \\
\hline 50 & 63 & $\mathrm{M}$ & 1 & $1 b$ & $\mathrm{sm} 3$ & 0 & 25 & L0 & V0 \\
\hline 4 & 64 & $\mathrm{M}$ & 2 & $1 b$ & sm3 & 1 & 19 & L1 & V0 \\
\hline 37 & 71 & $\mathrm{~F}$ & 2 & $1 b$ & sm3 & 0 & 29 & L0 & Vo \\
\hline 60 & 53 & $\mathrm{M}$ & 2 & $1 b$ & $\mathrm{sm} 3$ & 0 & 21 & L0 & V0 \\
\hline 6 & 71 & $\mathrm{M}$ & 3 & $1 b$ & sm3 & 1 & 42 & L1 & V0 \\
\hline 41 & 62 & $\mathrm{M}$ & 3 & $1 b$ & $\mathrm{sm} 3$ & 0 & 37 & L1 & V0 \\
\hline 42 & 67 & $\mathrm{M}$ & 3 & $1 b$ & $\operatorname{sm} 3$ & 3 & 74 & L1 & V0 \\
\hline 45 & 57 & $\mathrm{M}$ & 3 & $1 b$ & sm3 & 3 & 34 & L1 & V0 \\
\hline 46 & 65 & $\mathrm{M}$ & 3 & $1 b$ & $\mathrm{sm} 3$ & 0 & 24 & L0 & Vo \\
\hline 48 & 48 & $\mathrm{M}$ & 3 & $1 b$ & sm3 & 0 & 19 & L1 & V0 \\
\hline 51 & 76 & $\mathrm{~F}$ & 3 & $1 b$ & $\operatorname{sm} 3$ & 0 & 31 & L1 & V0 \\
\hline
\end{tabular}

F, female; M, male; $\mathrm{m}$, mucosal infiltration of lamina propria in its upper third (m1) or total mucosal layer (m3); sm, submucosal infiltration of upper (sm1), intermediate third (sm2) or to total layer (sm3); LN, lymph node; +, positive; $n$, total number; $\mathrm{pL}$, status of lymph vessel infiltration; pV, status of blood vessel infiltration; ER, endoscopic mucosal resection. were operated on between 2000 and 2005 (Table 1). Overall, 133 lesions of Barrett's disease were analyzed in these 29 patients $(\mathrm{M}: \mathrm{F}=5: 1)$. From a total of 203 specimens taken from these 29 patients, 77 specimens (60 biopsy and 17 surgical specimens) were included in this study. The age at surgery ranged between 48 and 81 years (median age 67 years). The early cancers demonstrated were limited to mucosal carcinoma in $28 \%(8 / 29$, pT1a; three $\mathrm{m} 1$, five $\mathrm{m} 3$ ) and infiltrated the submucosal layer in $72 \%$ (21/29, pT1b; seven sm1, two sm2, $12 \mathrm{sm} 3)$. In total $31 \%(9 / 29)$ demonstrated lymph vessel infiltration and $17 \%(5 / 29)$ showed positive lymph nodes (1-3 positive lymph nodes). The classification of tumor stage was performed on the basis that mucosa and submucosa were divided into three-thirds. The upper third was classified as level 1, middle third as level 2 and lower third as level 3 in mucosa and submucosa, respectively. The lymph-node status was determined by serial sections of each lymph node in 7-74 prepared nodes (mean: 27 lymph nodes per case) according to protocols used for sentinel lymph-node analysis in breast cancer. All nodal-positive cases demonstrated lymphatic vessel infiltration in the biopsy or endoscopic resection specimen.

\section{Immunohistochemistry}

We analyzed a multi-tissue array from each patient with reactive and neoplastic lesions of the disease by immunohistochemistry. There were 30 Barrett's epithelium negative for dysplasia and columnar epithelial cell changes indefinite for dysplasia (Barrett's epithelium), 30 Barrett's epithelium with columnar epithelial cell changes indefinite for dysplasia, 20 Barrett's epithelium with low-grade dysplasia, 23 Barrett's epithelium with highgrade dysplasia, and 24 early Barrett's adenocarcinoma. All columnar epithelial cell changes indefinite for dysplasia specimens of patients included in our cohort were examined in this study. The areas with Barrett's epithelium, columnar epithelial cell changes indefinite for dysplasia, low-grade dysplasia, or high-grade dysplasia we chose to examine in our study were not taken from the lateral margins of the invasive carcinoma. After deparaffinization, these arrays of formalin-fixed tissue sections (3- $\mu \mathrm{m}$ thick) were rehydrated, immersed in preheated target retrieval solution $\mathrm{pH} 9$ (\#S2367; Dako) and treated with heat for 20 min in a steamer. The slides were stained with the monoclonal anti-AMACR antibody p504S (clone 13H4, 1:500 dilution; Bioprime, Germany; Dako Autostainer; LSAB Detection System, \#K5005). Two different pathologists evaluated the immunohistochemical stainings for the presence and the extent of AMACR expression in a blinded fashion, designating samples according to Lisovsky et al, ${ }^{7}$ as negative ( 0 to $<5 \%$ cells positive), $1+(5-14 \%$ of cells positive), 
$2+(15-50 \%$ of cells positive), or $3+(>50 \%$ of cells positive). The histological criteria for dysplasia are summarized by Kerkhof et al. ${ }^{11}$

\section{Statistical Analysis}

The sensitivity of AMACR for dysplasia (Table 2) was calculated as the fraction of biopsies with dysplasia that stained positively for AMACR. The specificity of AMACR for dysplasia (Table 2) was calculated as the fraction of biopsies considered negative for dysplasia that were also negative for AMACR. Biopsies graded as columnar epithelial cell changes indefinite for dysplasia were not included in specificity calculation, as by definition, columnar epithelial cell changes indefinite for dysplasia foci are not considered definitely negative for dysplasia. For each sensitivity and specificity an exact $95 \%$ confidence interval was given. A Wilcoxon test was performed to compare AMACR staining scores between two groups with poor tumor grade and lymph vessel invasion (data not shown).

\section{Results}

\section{Immunohistochemistry}

A total of 133 reactive and neoplastic lesions of Barrett's disease were analyzed. All lesions were stained with AMACR. AMACR was negative in biopsies negative for dysplasia (Barrett's epithelium; Figure 1a and b), whereas $27 \%(8 / 30)$ of cases of columnar epithelial cell changes indefinite for dysplasia (Figure 1c and d) were positive for AMACR. In total $91 \%$ of cases with low-grade dysplasia (Figure 1e and f) were AMACR-positive and $96 \%$ of cases with high-grade dysplasia (Figure 2a and b) and early Barrett's adenocarcinoma (Figure 2c and d) were positive for AMACR. The sensitivity of AMACR for the detection of dysplasia in Barrett's epithelium in our cohort was 91\% for low-grade dysplasia, 96\% for high-grade dysplasia, and $96 \%$ for early Barrett's adenocarcinoma. All data are summarized in Table 2 . The specificity was $100 \%$. The $95 \%$ confidence interval was 0.91 (0.72-0.99) for low-grade dysplasia, 0.96 (0.79-1.0) for high-grade dysplasia, and $0.96(0.8-1.0)$ for early Barrett's adenocarcinoma.

\section{Lymph Vessel Infiltrations and Lymph Nodes of Early Barrett's Adenocarcinoma}

\section{Mucosal Adenocarcinoma}

None of the eight mucosal carcinomas demonstrated positive lymph nodes (7-31 lymph nodes were examined) or lymph vessel infiltration. These patients had undergone 0-7 endoscopic resections in the past (median 1, mean 2).

\section{Submucosal Adenocarcinoma}

One out of seven (14\%) adenocarcinomas with submucosal infiltration (sm1) demonstrated positive lymph-node status (1/40 lymph nodes). This grade 3 carcinoma also demonstrated venous and lymphatic vessel infiltration. Endoscopic resection was performed 0-2 times before surgery (median 1; mean 0.86).

Four out of fourteen $(29 \%)$ adenocarcinomas with infiltration (sm2 or sm3) demonstrated positive lymph-node status (1-3 of 19-74 lymph nodes). In

Table 2 AMACR expression in Barrett's esophagus and associated neoplastic lesions

\begin{tabular}{|c|c|c|c|c|c|c|c|c|}
\hline \multirow[t]{2}{*}{ Lesion } & \multicolumn{4}{|c|}{ Score } & \multirow{2}{*}{$\begin{array}{l}\text { Cases } \\
\text { Total }\end{array}$} & \multirow{2}{*}{$\begin{array}{c}\text { Positive cases } \\
\text { \% }\end{array}$} & \multirow{2}{*}{$\begin{array}{c}\text { Sensitivity } \\
\%\end{array}$} & \multirow[t]{2}{*}{ Reference } \\
\hline & $\mathrm{O}$ & $1+$ & $2+$ & $3+$ & & & & \\
\hline \multirow{3}{*}{ Barrett's epithelium } & 7 & 0 & 0 & 0 & 7 & 0 & & Lisovsky et $a l^{8}$ \\
\hline & 36 & 0 & 0 & 0 & 36 & 0 & & Dorer et $a l^{7}$ \\
\hline & 30 & 0 & 0 & 0 & 30 & 0 & & Present study \\
\hline \multirow{3}{*}{$\begin{array}{l}\text { Columnar epithelial cell } \\
\text { changes indefinite for dysplasia }\end{array}$} & 16 & 0 & 0 & 0 & 16 & 0 & & Lisovsky et $a l^{8}$ \\
\hline & 11 & 1 & 2 & 0 & 14 & 21.4 & & Dorer et $a l^{7}$ \\
\hline & 22 & 8 & 0 & 0 & 30 & 26.7 & & Present study \\
\hline \multirow[t]{3}{*}{ Low-grade dysplasia } & 17 & 1 & 0 & 1 & 19 & 10.5 & & Lisovsky et $a l^{8}$ \\
\hline & 10 & 2 & 3 & 1 & 16 & 37.5 & 38 & Dorer et $a l^{7}$ \\
\hline & 2 & 10 & 8 & 0 & 20 & 90 & 91.3 & Present study \\
\hline \multirow[t]{3}{*}{ High-grade dysplasia } & 8 & 7 & 5 & 2 & 22 & 63.6 & 64 & Lisovsky et $a l^{8}$ \\
\hline & 6 & 9 & 8 & 9 & 32 & 81.3 & 81 & Dorer et $a l^{7}$ \\
\hline & 1 & 3 & 9 & 10 & 23 & 95.7 & 95.8 & Present study \\
\hline \multirow[t]{3}{*}{ Adenocarcinoma } & 4 & 6 & 4 & 2 & 16 & 75 & & Lisovsky et $a l^{8}$ \\
\hline & 1 & 5 & 8 & 13 & 27 & 96.3 & 72 & Dorer et $a l^{7}$ \\
\hline & 1 & 3 & 10 & 10 & 24 & 95.8 & 96 & Present study \\
\hline
\end{tabular}



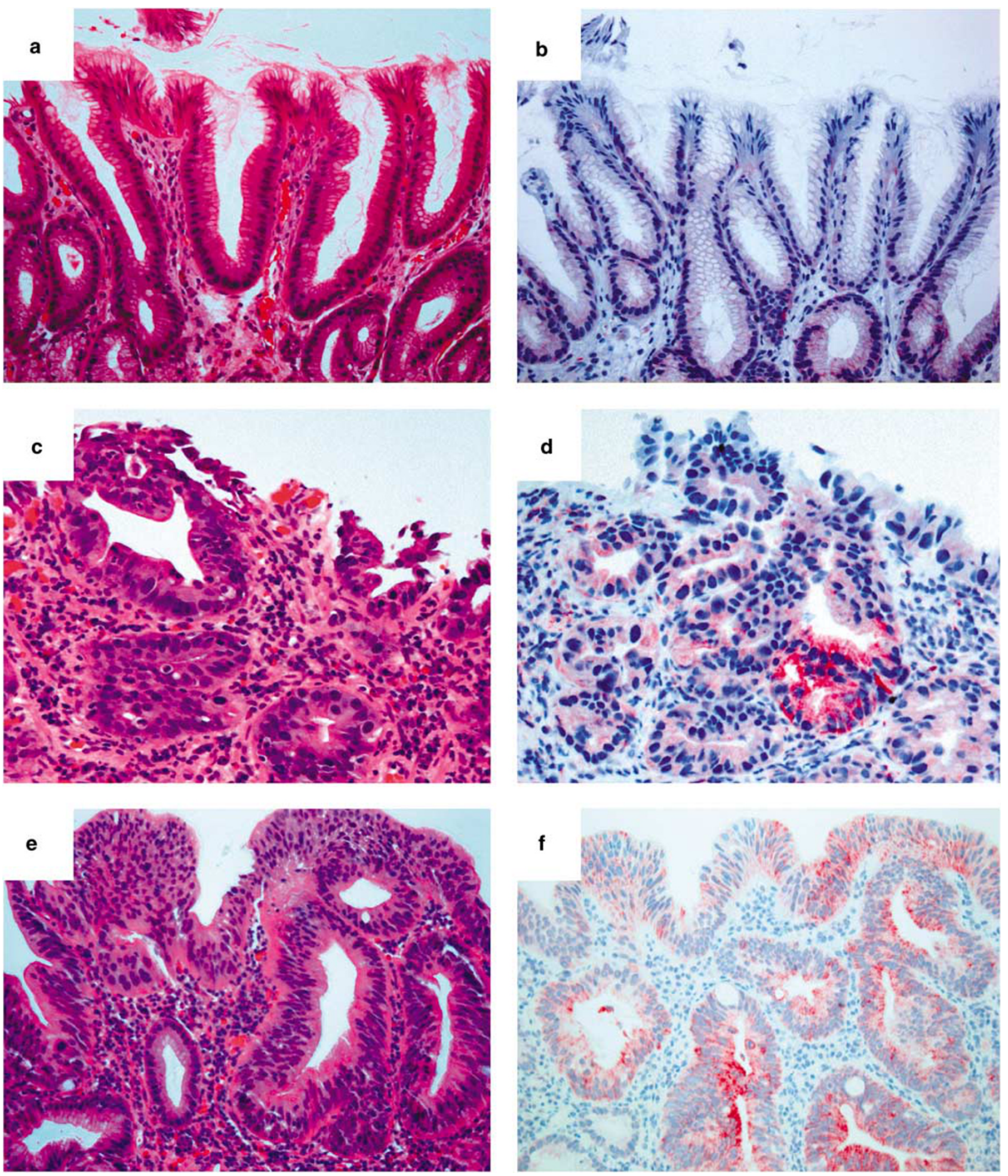

Figure 1 Hematoxylin and eosin staining and immunohistochemical expression of AMACR $(\times 20)$. (a) Barrett epithelium considered negative for dysplasia or reactive atypia (b) is negative for AMACR. (c) Coumunar epithelial cell changes indefinite for dysplasia (d) are weakly AMACR-positive. (e) Low-grade dysplasia in Barrett's esophagus. (f) AMACR is positive in low-grade dysplasia.

cases, endoscopic resection had previously been performed up to five times (median 0; mean 1) for high-grade dysplasia or mucosal adenocarcinoma in Barrett's esophagus. All data are summarized in Table 1.

\section{Lymph Vessel Infiltration and Poor Tumor Grade}

AMACR staining scores were analyzed between two groups with poor tumor grade and

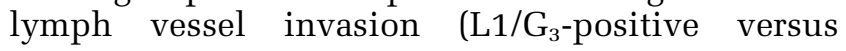



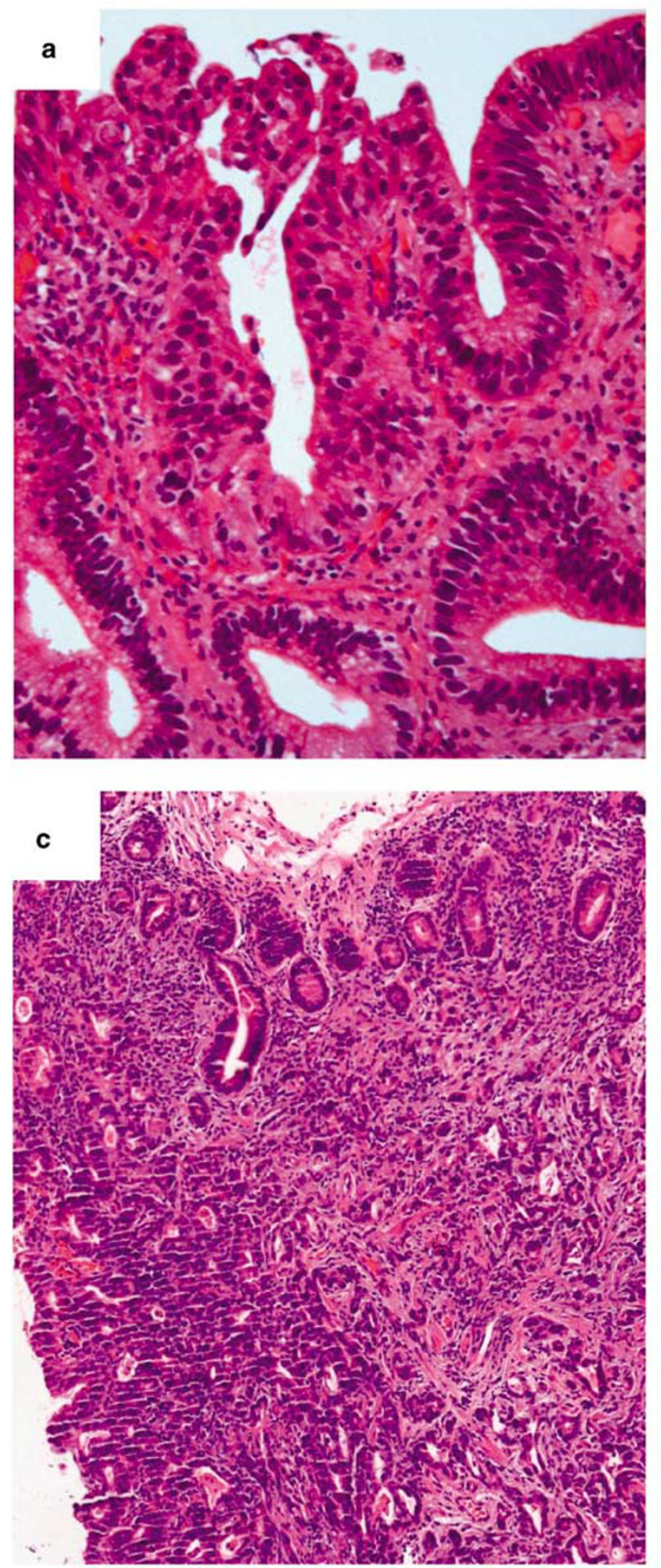
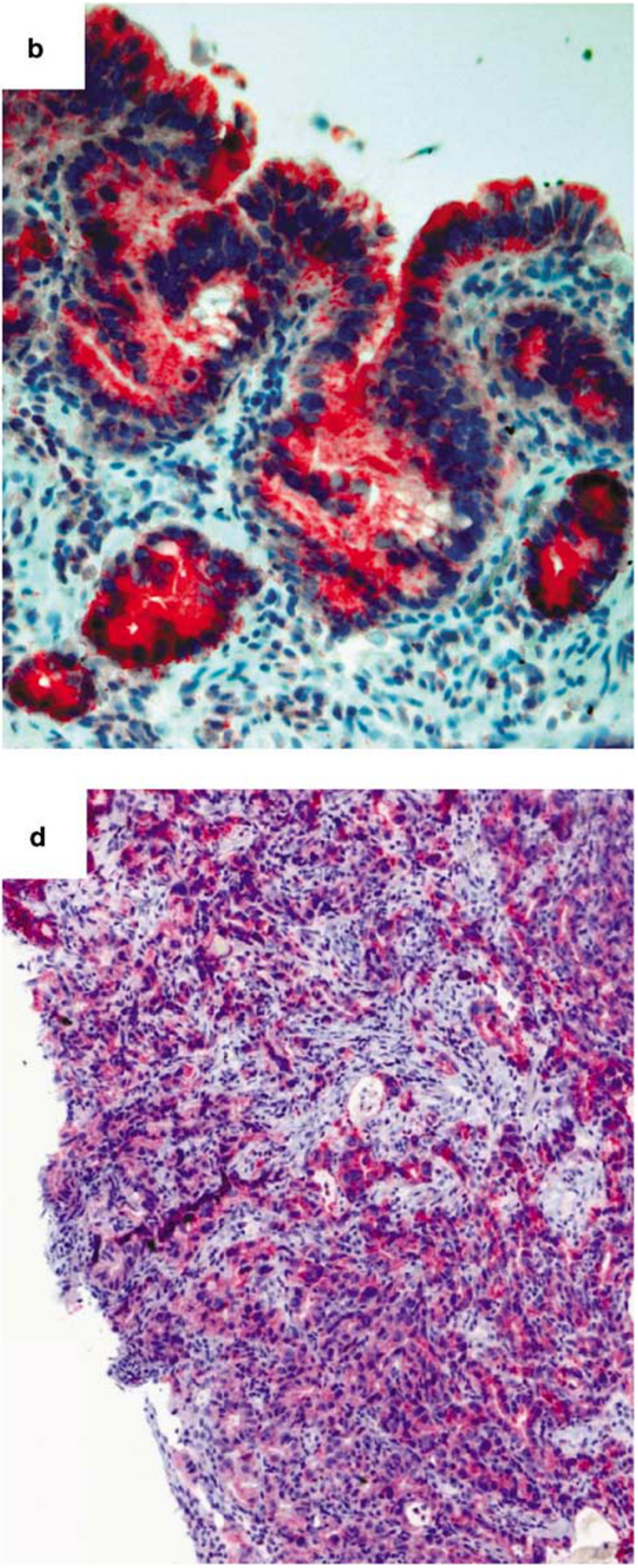

Figure 2 Hematoxylin and eosin staining and immunohistochemical expression of AMACR $(\times 20)$. (a) High-grade dysplasia in Barrett's esophagus. (b) AMACR is positive in high-grade dysplasia. (c) Invasive early Barrett's adenocarcinoma (d) demonstrates positive AMACR immunoreactivity.

$\mathrm{L} 1 / \mathrm{G}_{3}$-negative). Lymph vessel invasion and poor tumor grade was not significantly correlated with the staining score $(P>0.1$; data not shown).

\section{Discussion}

Endoscopic resection had been performed in 16/29 patients (5/8 mucosal adenocarcinoma, 11/21 
submucosal adenocarcinoma) before surgery. Surgery is still the therapy of choice in cases with Barrett's adenocarcinoma infiltrating submucosal layers because of a higher risk of lymphatic vessel infiltration. ${ }^{6}$ In our cohort, none of the mucosal Barrett's adenocarcinomas $(n=7)$ demonstrated lymphatic vessel infiltration or positive lymph nodes, and submucosal Barrett's adenocarcinomas demonstrated in 29\% (sm1) and 50\% (sm2/3) lymphatic vessel infiltration, whereas positive lymph nodes were found in $24 \%$ of submucosal adenocarcinomas $(n=21 ; 14 \%$ sm1; $29 \% \mathrm{sm} 2 / 3)$. These data confirm the data recently published by Bollschweiler et al. ${ }^{12}$ These authors examined 14 mucosal and 22 submucosal early adenocarcinomas in Barrett's disease. None of their mucosal cancers demonstrated positive lymph nodes, whereas $21 \%$ of submucosal cancers (11\% sm $1 ; 44 \%$ sm3) were positive (pN1). In summary, although endoscopic resection cannot currently be recommended in cases of Barrett's adenocarcinoma with submucosal infiltration, it is gaining in popularity as a curative technique. ${ }^{13-16}$

Recently, Lin et $a 1^{17}$ demonstrated that the lack or low-intensity staining of AMACR in a cohort of 163 colorectal carcinoma is significantly correlated with poor tumor differentiation $(P=0.021)$, and presence of lymphovascular invasion $(P<0.032)$. In our study, we did not find a significant correlation between staining score and these criteria.

Several studies have focused on finding molecular markers for reducing interobserver variability in the histopathological diagnosis of Barrett's neoplastic lesions. So far, no reliable prognostic markers for monitoring the neoplastic progression of Barrett's esophagus have been found. As with p53 and p16 $6^{\mathrm{INK} 4 \mathrm{~A}}$ other molecules-c-erbB2, cyclin D1, p27 ${ }^{\mathrm{KiP} 1}$ EGFR, COX-2, and $\beta$-catenin-have been found to be disappointing as prognostic markers in Barrett's esophagus. ${ }^{18-20}$ CD1a has also been tested as a possible biomarker of Barrett's metaplasia, in the hope that its expression might help in predicting the prognosis of this pathology. ${ }^{21}$ The markers p53 and c-erbB2 in particular have been controversially discussed. TP53 was found to have a low sensitivity, but p53 mutational status may ultimately be a component of such a molecular marker panel. ${ }^{4,20}$ C-erbB2/Her-2/neu could not be demonstrated as a molecular marker by Langer et $a l^{18}$ but fluorescence in situ hybridization (FISH) analysis demonstrated amplification/overexpression of Her-2/neu as a marker of progression from Barrett's epithelium to dysplasia. ${ }^{22}$ The authors suggested that FISH represents a useful diagnostic tool for selecting patients for more targeted therapeutic approaches.

Recently, two studies focused AMACR in Barrett's neoplastic lesions. ${ }^{7,8}$ AMACR is known to be expressed in prostate and colon cancer. Both studies demonstrated the expression of AMACR as a highly specific marker in Barrett's neoplastic lesions. Columnar epithelial cell changes indefinite for dysplasia were positive in $3 / 30$ cases in these studies. Follow-up was available for 11 of these patients with columnar epithelial cell changes indefinite for dysplasia. After 2 months, Barrett's adenocarcinoma was diagnosed in one of the three cases with AMACR immunoreactivity columnar epithelial cell changes indefinite for dysplasia. There was no follow-up in the other two patients. Is AMACR expression also a diagnostic marker for neoplastic transformation in Barrett's disease? We retrospectively analyzed 29 cases with Barrett's adenocarcinoma treated with surgery. Follow-up was at least 12 months. We found 133 different lesions of reactive and neoplastic lesions in Barrett's disease. Previous studies suggested that columnar epithelial cell changes indefinite for dysplasia in Barrett's disease in which AMACR is expressed indicate neoplastic progression of the disease. In the present study, only $27 \%$ of columnar epithelial cell changes indefinite for dysplasia demonstrated AMACR expression. Our data are similar to the result from Dorer and Odze ${ }^{7}$ concerning columnar epithelial cell changes indefinite for dysplasia (Table 2). Furthermore, the previous studies demonstrated $63.6-81.3 \%$ AMACR immunoreactivity in high-grade dysplasia and $75-96.3 \%$ of Barrett's adenocarcinomas positive for AMACR., ${ }^{7,8}$ Again, we achieved similar results from Dorer and Odze. ${ }^{7}$ Interestingly, we demonstrated $90 \%$ of low-grade dysplasia to have AMACR immunoreactivity. This is much higher than previously published data, with $10.5 \%$ found by Lisovsky et $a l^{8}$ and $37.5 \%$ demonstrated by Dorer and Odze. ${ }^{7}$

These differences cannot be explained by method differences, as we used nearly identical methods to Dorer et $a .^{7}$ The difference in results concerning low-grade dysplasia might be that our cohort is characterized by dysplasia carcinoma sequence. The sensitivity of AMACR expression in low-grade dysplasia subsequently progressing to early Barrett's adenocarcinoma is significantly higher in our study compared with previous data. Low-grade dysplasia may be transient and does not always progress to cancer. The diagnosis of low-grade dysplasia is difficult, general pathologists are frequently uncertain about the diagnosis of low-grade dysplasia and its follow-up risks. ${ }^{20}$ Therefore, AMACR expression in low-grade dysplasia might be a new diagnostic marker in Barrett's disease. Furthermore, lesions classified histologically as 'indefinite' might need to be reclassified after AMACR staining as negative or positive based on the staining pattern. In order to clarify this point, further investigations are needed with a well-defined control group with at least 5 -years follow-up.

In conclusion, in our cohort of 29 patients with early Barrett's adenocarcinomas we found much higher rates of AMACR immunoreactivity in neoplastic lesions of Barrett's disease than previous studies demonstrated. We suggest that low-grade dysplasia with AMACR immunoreactivity should be 
controlled much more frequently by endoscopic biopsy because this might be a new diagnostic parameter in low-grade Barrett's neoplastic lesions. Further studies are needed to investigate this point with well-defined controls having at least 5-years follow-up.

\section{Acknowledgement}

We acknowledge Dagmar Clauss, Sandra Stolzenberger and To-Anh Du and Torsten Fink for skillful technical assistance, Martina Kron for help with the statistical analysis, and Anne Fitzgerald for editorial help.

\section{References}

1 Ronkainen J, Aro P, Storskrubb T, et al. Prevalence of Barrett's esophagus in the general population: an endoscopic study. Gastroenterology 2005;129:1825-1831.

2 Veldhuyzen van Zanten SJ, Thomson AB, Barkun AN, et al. The prevalence of Barrett's oesophagus in a cohort of 1040 Canadian primary care patients with uninvestigated dyspepsia undergoing prompt endoscopy. Aliment Pharmacol Ther 2006;23:595-599.

3 Vieth M, Schubert B, Lang-Schwarz K, et al. Frequency of Barrett's neoplasia after initial negative endoscopy with biopsy: a long-term histopathological follow-up study. Endoscopy 2006;38:1201-1205.

4 Keswani RN, Noffsinger A, Waxman I, et al. Clinical use of p53 in Barrett's esophagus. Cancer Epidemiol Biomarkers Prev 2006;15:1243-1249.

5 Eguchi T, Nakanishi Y, Shimoda T, et al. Histopathological criteria for additional treatment after endoscopic mucosal resection for esophageal cancer: analysis of 464 surgically resected cases. Mod Pathol 2006;19:475-480.

6 Stein HJ, Feith M. Surgical strategies for early esophageal adenocarcinoma. Best Pract Res Clin Gastroenterol 2005;19:927-940.

7 Dorer R, Odze RD. AMACR immunostaining is useful in detecting dysplastic epithelium in Barrett's esophagus, ulcerative colitis, and Crohn's disease. Am J Surg Pathol 2006;30:871-877.

8 Lisovsky M, Falkowski O, Bhuiya T. Expression of alpha-methylacyl-coenzyme A racemase in dysplastic Barrett's epithelium. Hum Pathol 2006;37:1601-1606.

9 Nassar A, Amin MB, Sexton DG, et al. Utility of alphamethyacyl coenzyme A racemase (p504s antibody) as a diagnostic immunohistochemical marker for cancer. Appl Immunohistochem Mol Morphol 2005;13:252-255.

10 Schmitz W, Fingerhut R, Conzelmann E. Purification and properties of an alpha-methylacyl-CoA racemase from rat liver. Eur J Biochem 1994;222:313-323.

11 Kerkhof M, van Dekken H, Steyerberg EW, et al. Grading of dysplasia in Barrett's oesophagus: substantial interobserver variation between general and gastrointestinal pathologists. Histopathol 2007;50:920-927.

12 Bollschweiler E, Baldus SE, Schroeder W, et al. High rate of lymph-node metastasis in submucosal esophageal squamous-cell carcinomas and adenocarcinomas. Endoscopy 2006;38:149-156.

13 Buskens CJ, Hulscher JB, van Gulik TM, et al. Histopathologic evaluation of an animal model for Barrett's esophagus and adenocarcinoma of the distal esophagus. J Surg Res 2006;135:337-344.

14 May A, Nachbar L, Pohl J, et al. Endoscopic interventions in the small bowel using double balloon enteroscopy: feasibility and limitations. Am J Gastroenterol 2007;102:527-535.

15 Pech O, Vieth M, Schmitz D, et al. Conclusions from the histological diagnosis of low-grade intraepithelial neoplasia in Barrett's oesophagus. Scand J Gastroenterol 2007;42:682-688.

16 Westerterp M, Koppert LB, Buskens CJ, et al. Outcome of surgical treatment for early adenocarcinoma of the esophagus or gastro-esophageal junction. Virchows Arch 2005;446:497-504.

17 Lin A, Weiser MR, Klimstra DS, et al. Differential expression of alpha-methylacyl-coenzyme A racemase in colorectal carcinoma bears clinical and pathologic significance. Hum Pathol 2007;38:850-856.

18 Langer R, von Rahden HBA, Nahrig JA, et al. Prognostic significance of expression patterns of c-erbB-2, p53, p16INK4A, p27KIP1, cyclin D1 and epidermal growth factor receptor in eosophageal adenocarcinoma: a tissue microarray study. J Clin Pathol 2006;59: 631-634.

19 Murray L, Sedo A, Scott M, et al. TP53 and progression of Barrett's metaplasia to esophageal adenocarinoma in a UK population cohort. Gut 2006;55:1390-1397.

20 Odze RD. Diagnosis and grading of dysplasia in Barrett's oesophagus. J Clin Pathol 2006;59:1029-1038.

21 Cappello F, Rappa F, Anzalone R, et al. CD1a expression by Barrett's metaplasia of gastric type may help to predict its evolution towards cancer. Br J Cancer 2005;92:888-890.

22 Rossi E, Villanacci V, Bassotti G, et al. Her-2/neu in Barrett esophagus. A comparative study between histology, immunohistochemistry, and fluorescence in situ hybridization. Diagn Mol Pathol 2006;15: 125-130. 